Rev Biomed 2002; 13:293-294.

\title{
Breve consideración sobre la clonación de seres humanos.
}

Carta al Editor

Jesús Quintanilla-Osorio.

Servicios Estatales de Salud en Quintana Roo, Chetumal, Quintana Roo, México.

La justificación histórica de la investigación en seres humanos, ha sido siempre la búsqueda de nuevos horizontes para la ciencia. La Alemania hitleriana utilizaba seres humanos como conejillos de laboratorio, bajo el pretexto de la raza o la religión, y se cometieron aberraciones contranatura buscando descubrir a la raza perfecta. Ahora, la clonación, que supone la manipulación genética de células madre y la inserción del huevo fecundado en un organismo distinto, requirió de miles de intentos para traer al mundo a la famosa Dolly, uno de los hitos de la tecnología biocientífica del siglo XX.

Trasladar esta experiencia a la creación de seres humanos supone la violación más abierta a las leyes naturales, porque aunque se logre una copia idéntica de un organismo humano, es evidente que se está penetrando en los linderos de la vida, y ninguna justificación bioética puede avalar esta intrusión a un campo que nos está vedado por el propio bien de la humanidad. La crasa posibilidad de la utilización de esta tecnología para fines distintos a los puramente biológicos, conlleva el riesgo de "fabricar" seres por catálogo, una idea que se antojaba extraída de la ciencia-fícción hasta los anuncios de científicos europeos trabajando en el primer clon humano.

El temor de el surgimiento de monstruosas criaturas perfectas que pueden desplazar a los meramente humanos, es una espantosa posibilidad, donde el ser humano, debería competir con humanos sintéticos.

La ciencia no debe traspasar los límites de la experiencia humana, ni moverse por intereses ajenos a la mejoría en la calidad de vida de los hombres. Existen ciertamente, problemas estremecedoramente intensos, como el hambre en las comunidades indígenas de nuestro México, el descomunal avance del Síndrome de Inmunodeficiencia Adquirida en el Continente Africano, la pobreza de países en esa misma región, que debieran fortalecerse los proyectos destinados al aumento en la producción de alimentos, a la búsqueda de la cura de las llamadas enfermedades mortales o la erradicación de padecimientos endémicos en las regiones más empobrecidas de nuestro mundo.

La clonación parece un intento más para controlar la producción de seres humanos, una forma más abyecta de esclavismo donde nunca podrá existir

Solicitud de sobretiros: T.V.S. Jesús Quintanilla-Osorio, Tlaxcalaltongo 250, Col. Carranza, Chetumal, Quintana Roo, México. Recibido el 17/Junio/2002. Aceptado para publicación 12/Julio/2002 


\section{J. Quintanilla-Osorio.}

conciencia de la propia identidad biológica, si no la idea de ser el resultado de un estudio de laboratorio.

Cuando la ciencia traspasa los límites de la vida, utilizando el poder que les es conferido, es conveniente recordar el peligro que entraña la frase de Lord Acton, "el poder absoluto, corrompe absolutamente". La ciencia tiene el deber de utilizar su poder para llevar a la raza humana, a un estadio de concordia y paz entre los hombres.

Palabras clave: Clonación, bioética. 